\title{
New Clinical Faculty Training Program: Transforming Practicing Dentists into Part-Time Dental Faculty Members
}

\author{
Brooke N. Adams, DDS; Michele L. Kirkup, DDS; Lisa H. Willis, DDS, MSD; \\ Paul E. Reifeis, DDS, JD, MSD
}

Abstract: At Indiana University School of Dentistry, a New Clinical Faculty Training (NCFT) program was created with the primary goals of informing new part-time faculty members of clinical policies and assessment guidelines and thus developing qualified and satisfied faculty members. The aim of this study was to determine if participation in the training program improved the participants' satisfaction and competence in comparison to their colleagues who did not participate in the program. Two cohorts were compared: a control group of part-time faculty members who did not receive formal training when they were hired $(n=21$; response rate 58.3\%); and the intervention group, who had participated in the NCFT program $(n=12$; response rate $80 \%)$. A survey of faculty members in the control group gathered information on their experiences when initially hired, and a pretest was administered to measure their knowledge of clinical policies. After the control group was given an overview of the program, their feedback was collected through post surveys, and a posttest identical to the pretest was given that found statistically significant increases on questions one $(\mathrm{p}=0.003)$ and four $(\mathrm{p}=0.025)$. In February 2014, 15 new faculty members participated in the pilot implementation of the NCFT program. Of those 15, 12 (the intervention group) completed follow-up surveys identical to the pre survey used with the control group. Statistically significant differences were found for the factors clinical teaching $(\mathrm{p}=0.005)$ and assessment training $(\mathrm{p}=0.008)$ with better responses for the NCFT group. These results suggest that participation in the program was associated with improved clinical teaching knowledge and job satisfaction.

Dr. Adams is Clinical Assistant Professor, Cariology, Operative Dentistry, and Public Health Department, Indiana University School of Dentistry; Dr. Kirkup is Clinical Assistant Professor, Department of Prosthodontics, Indiana University School of Dentistry; Dr. Willis is Clinical Assistant Professor, Cariology, Operative Dentistry, and Public Health Department, Indiana University School of Dentistry; and Dr. Reifeis is Clinical Assistant Professor, Cariology, Operative Dentistry, and Public Health Department, Indiana University School of Dentistry. Direct correspondence to Dr. Brooke Adams, Department of Cariology, Operative Dentistry, and Public Health, Indiana University School of Dentistry, 1121 West Michigan Street, Rm. 316, Indianapolis, IN 46202; 317-278-3398; bnadams2@iu.edu.

Keywords: dental education, dental faculty, job satisfaction, program development, training, faculty vacancies, part-time faculty

Submitted for publication 7/29/16; accepted 12/8/16

doi: $10.21815 / J D E .016 .030$

$\mathrm{T}$ The number of part-time faculty vacancies in U.S. dental schools has consistently been much lower than the number of full-time vacancies, but the majority of vacancies in both categories are in the clinical sciences. ${ }^{1}$ While over half of all new faculty members in 2014-15 came from private practice, three-quarters of those (75.4\%) filled part-time positions. Like other dental schools, Indiana University School of Dentistry (IUSD) appoints many private practice dentists as part-time faculty members to instruct students in the predoctoral comprehensive care clinics. As Holyfield and Berry noted in 2008, these new faculty members entering academia from private practice bring a valuable "real world" perspective to the educational environment. ${ }^{2}$ We have also observed that the parttime faculty members' enthusiasm for passing on acquired knowledge and expertise to the dentists of tomorrow is appreciated by students as well as the full-time faculty, who cannot provide continual clinical coverage due to administrative, lecture, and laboratory responsibilities.

In the past, as was noted about new faculty members in endodontics, it was not unusual for schools to grant authority to practitioners to become clinical faculty instructors simply by giving them an identification card and having them begin teaching the same day. ${ }^{3}$ This on-the-job training may be even more challenging for faculty members who are employed on a part-time basis. Thus, over the past two decades, there has been increasing emphasis on preparing both full- and part-time faculty members for their teaching positions, as in the programs at Baylor College of Dentistry, New York University, and the University of Missouri-Kansas City. ${ }^{2,45}$ As Wilkerson and Irby noted, "Over time, teaching has come to be 
recognized as a skill associated with, but separate from, content expertise" (p. 388). ${ }^{6}$ Furthermore, instructors have the responsibilities of being both facilitators in learning and role models for students, which can be aided by formal educational training methods. ${ }^{3}$ Studies in dental hygiene education found that, if new faculty members were not helped to acquire the knowledge and skills to effectively teach students, outcomes may include varying instructional methods and frustration due to unfamiliarity with academic policies and procedures. ${ }^{7,8}$ The consequence of these problems can diminish student learning.

To properly prepare full- and part-time faculty members for successful and fulfilling careers in academia, it is necessary for dental schools to invest in faculty development programs and mentorship. Dentists who enter academia from private practice need particular preparation to acclimate them to a teaching position. Research in other health professions education has found that giving guidance to new faculty members can both aid their professional development and increase their confidence and morale, leading to better retention rates. ${ }^{9,10}$

An important concept is that faculty members should be given development programs that match their level of involvement in education. ${ }^{6}$ For example, novice faculty members should be introduced to basic teaching aptitudes as well as to the institution itself and academic expectations. This view is supported by Bland et al., who noted that medical schools should focus on the areas of development most needed and create effective strategies for addressing these deficiencies. ${ }^{11}$ New faculty members should perceive that they are worth the investment of the institution's time and that faculty development programs are readily available for them.

With these guidelines in mind, a New Clinical Faculty Training (NCFT) program was developed at IUSD with the primary purpose of informing incoming part-time faculty members of job expectations, clinical policies, procedural criteria, and teaching guidelines for student assessment. Due to our school's increasing reliance on part-time faculty members, the goal of the NCFT program is to transform private practice dentists into effective part-time clinical educators who consider themselves to be knowledgeable and valued members of the dental faculty team. With no prior faculty training program in place, our hypothesis was that the NCFT program would improve our approach to training and communicating with new part-time faculty members. While the benefits of faculty orientation and development programs are widely acknowledged, there is little documentation in the literature regarding programs tailored to the distinctive needs of part-time faculty members. The aim of this study was to determine if participation in the training program improved the participants' satisfaction and competence in comparison to their colleagues who did not participate in the program.

\section{Methods}

This study was found to be exempt from oversight by the Indiana University Institutional Review Board (\#1409077117). An IUSD NCFT ad hoc committee was formed in fall 2013 with the charge of designing a training program for new clinical faculty members. In January 2014, part-time faculty members attended one of four faculty development meetings about their teaching experiences. The meetings were designed in part to gather information regarding how these faculty members rated their experiences and training when they were hired as new faculty.

Of the 36 part-time clinical faculty members who attended those meetings, 21 agreed to participate in the study as a control group. At the beginning of the meetings, these faculty members were given pre surveys to measure their perceptions about satisfaction, communication, and appreciation when they were hired as new faculty. Response options for the items on this satisfaction survey were excellent, good, average, poor, and not applicable. Following that survey, the participants were given an overview of the NCFT program designed for new IUSD clinical faculty members. At the conclusion of the meetings, a post survey with the same items was distributed for the participants to rate the NCFT program's preview. The data were analyzed using descriptive statistics.

In addition, the NCFT committee developed a pretest with five true/false questions to measure these part-time faculty participants' existing knowledge of basic clinical policies and guidelines. The pretest was administered simultaneously with the satisfaction pre survey during the faculty development meetings. Following the overview of the NCFT program, the participants were retested using the same questions to determine if the information presented increased their knowledge of clinical guidelines. McNemar's test was utilized to examine the paired nominal data.

The NCFT program was launched in February 2014. As each new faculty member was hired, he or she was required to participate in a day-long orienta- 
tion that included meeting the administrative deans or departmental chairs to discuss job expectations, a tour of the facility, a human resources presentation to discuss credentialing, and an introduction to IUSD's electronic health record system (axiUm). Additionally, new faculty members attended a formalized two-hour presentation about the comprehensive care clinics, the teaching of clinical policies and procedures, and the training and evaluation of students using IUSD's formative assessment system. ${ }^{12}$ During this presentation, the new faculty members received teaching materials and instructional resources. Following the presentation, these new faculty members were paired with experienced clinical faculty mentors in the afternoon to observe the dynamics of the clinical setting.

As of June 2016, IUSD had trained 15 new faculty members (three full-time and 12 part-time) in the NCFT program. In fall 2015 and spring 2016, follow-up meetings were scheduled, and 12 of the 15 NCFT participants attended one of the sessions. Those 12 faculty members were the intervention group for the study. During the sessions, the participants completed a follow-up survey concerning their experiences as new faculty members. The five questions were identical to those on the pre survey completed by the control group in January 2014. The intervention group also completed a survey regarding how well the orientation process prepared them for teaching and their suggestions for improvement. Each component of the orientation day was evaluated on a rating scale with areas for open commentary.

A descriptive statistical analysis was performed on the NCFT participants' ratings on the follow-up survey. Ordered response categories comparing the existing part-time faculty members' pre survey results (control group) to the NCFT follow-up survey results (intervention group) were determined with Mantel-Haenszel chi-square statistics.

\section{Results}

In the control group, 21 of the 36 faculty members participated in the surveys, for a $58 \%$ response rate. All of those 21 faculty members were part-time. In the intervention group, 12 of the 15 faculty members participated in the surveys, for an $80 \%$ response rate. The intervention group was a combination of full-time and part-time faculty members, but the precise number of each was not determined. Since those trained in the NCFT program were three full-time and
12 part-time faculty members, it is clear that most of those 12 respondents were part-time, but up to three of them could have been full-time.

\section{Control Group's Results}

The control group's pre survey results showed their experiences as new faculty members ranged from excellent to poor. Of the respondents, $66.7 \%$ gave an excellent or good rating to the communication of their position expectations, while $9.5 \%$ rated this category as poor (Figure 1). Second, $42.9 \%$ of the respondents rated their training in clinical policies and procedures as excellent or good, 33.3\% rated it as average, and $19 \%$ rated it as poor. A key finding was that while $38.1 \%$ rated their training in assessing student performance as excellent or good, 14.3\% reported not receiving any assessment training. The respondents gave mixed opinions concerning their sense of appreciation from the administration and faculty as a new faculty member: $61.9 \%$ rated it as excellent or good, $28.6 \%$ rated it as average, and $9.5 \%$ rated it as poor.

After having received the description of the NCFT program, the post survey found that $100 \%$ of the respondents rated the presented information as excellent or good (Figure 2). In addition, $100 \%$ of the same cohort rated the information provided regarding assessment of students' clinical performance as excellent or good, and $90.5 \%$ selected an excellent rating for the launch of the NCFT program.

For the control group pretest and posttest comparison, we used McNemar's test to evaluate whether the percentage of test questions (TQ) answered correctly increased from the pre- to the posttest following the NCFT presentation. Statistically significant increases were found for TQ1 $(\mathrm{p}=0.003)$ and TQ4 $(\mathrm{p}=0.025)$, but no significant differences were found for TQ2 $(p=0.317)$, TQ3 $(p=0.083)$, or TQ5 ( $\mathrm{p}=0.157)$ (Table 1).

\section{NCFT Participants' Results}

Following the training program, the NCFT participants in the intervention group answered the same survey questions that the control group did on their pre survey. Of the NCFT respondents, $91.7 \%$ rated the communication of their position expectations as excellent or good, with the remaining $8.3 \%$ giving an average rating (Figure 3). In addition, $83.4 \%$ of the respondents rated their training in clinical policies and procedures as excellent or good, with one 


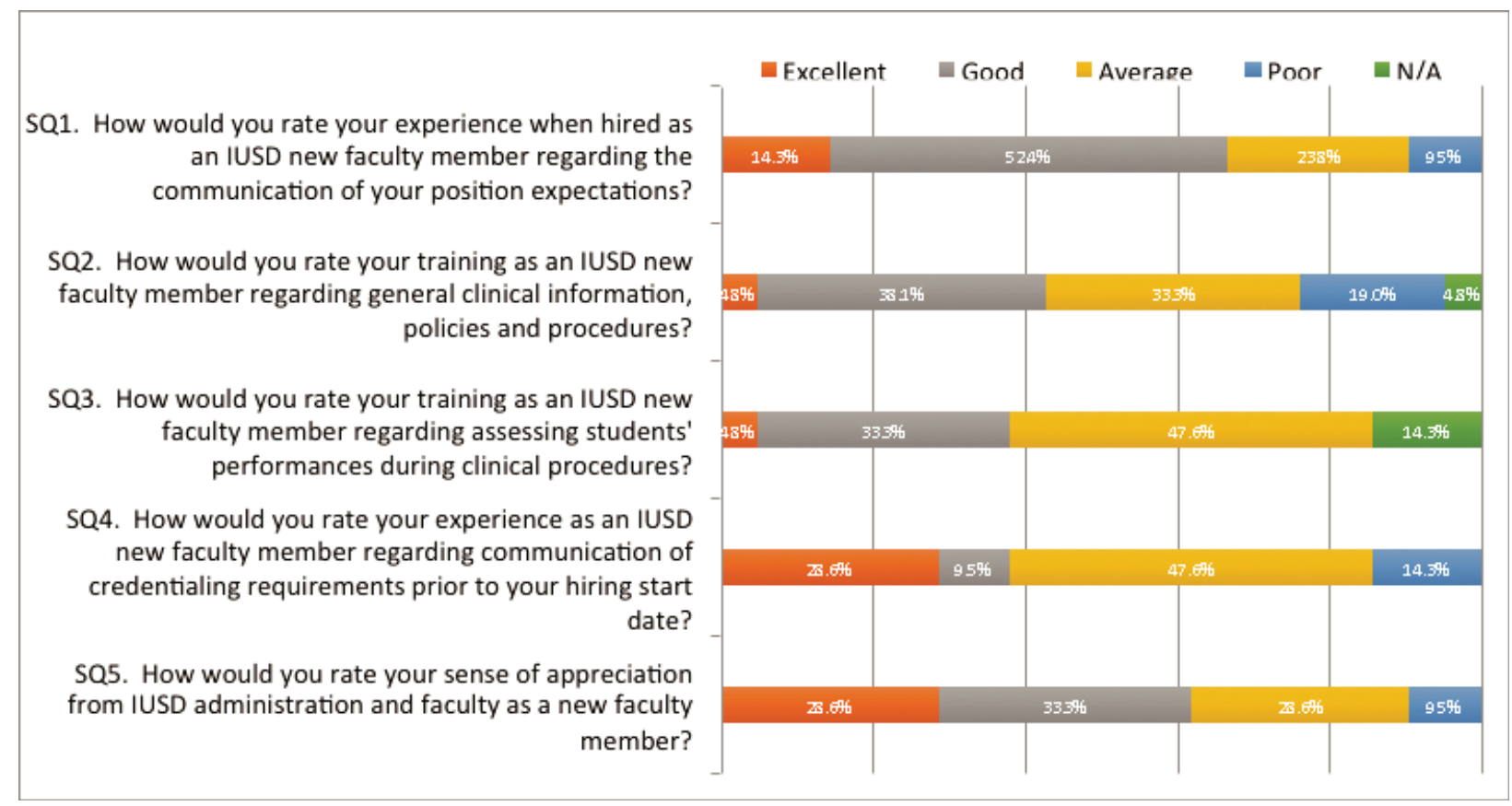

Figure 1. Pre survey of Indiana University School of Dentistry (IUSD) part-time faculty members prior to introduction of New Clinical Faculty Training program $(\mathrm{N}=21)$ : perceptions of their past orientation experiences

commenting the respondent "felt very comfortable the first day of clinic." Another respondent noted that, "as a non-IUSD graduate, it gave me an overview of clinic policy." The majority of the respondents $(83.3 \%)$ rated as excellent or good the program's training on student assessment in clinic. One participant indicated wanting more training on how to utilize clinical time to properly assess students and convey needed improvements. All the respondents in the intervention group gave an excellent or good rating for their sense of appreciation from IUSD administration and faculty. Multiple members of the control group commented that the orientation was a positive process and made them feel welcome.

We compared the control group pre survey results $(n=21)$ with the intervention group survey results $(n=12)$ using Mantel-Haenszel chi-square tests. Statistically significant differences were found for the survey questions (SQ) concerning training in clinical policies and procedures (SQ2: $\mathrm{p}=0.005)$ and the assessment training (SQ3: $\mathrm{p}=0.008$ ), with better responses for the NCFT intervention cohort (Table 2). No significant differences were found for the remaining questions: SQ1 ( $\mathrm{p}=0.109)$, SQ4 ( $\mathrm{p}=0.545)$, or SQ5 ( $\mathrm{p}=0.058)$.

\section{Discussion}

In January 2014, faculty development meetings were conducted to identify deficiencies in IUSD's training of new part-time faculty. Given that there was no formal faculty training program in place at that time, the NCFT committee speculated that these part-time faculty members may not have had satisfactory experiences when they were hired as new faculty and would fully support an NCFT program. Through the control group's pre surveys, the NCFT committee gained an understanding of the positive and negative aspects of their experiences when hired. After viewing the NCFT presentation, $95 \%$ of the control group gave an excellent or good rating on the post surveys regarding the launch of the program. After the NCFT program had been launched, committee members compared the survey results from the control group and the NCFT intervention group to assess the quality of the program.

Studies in nursing education have found that new faculty members should be provided clear expectations of their academic positions and that, without such, faculty may experience frustrations 


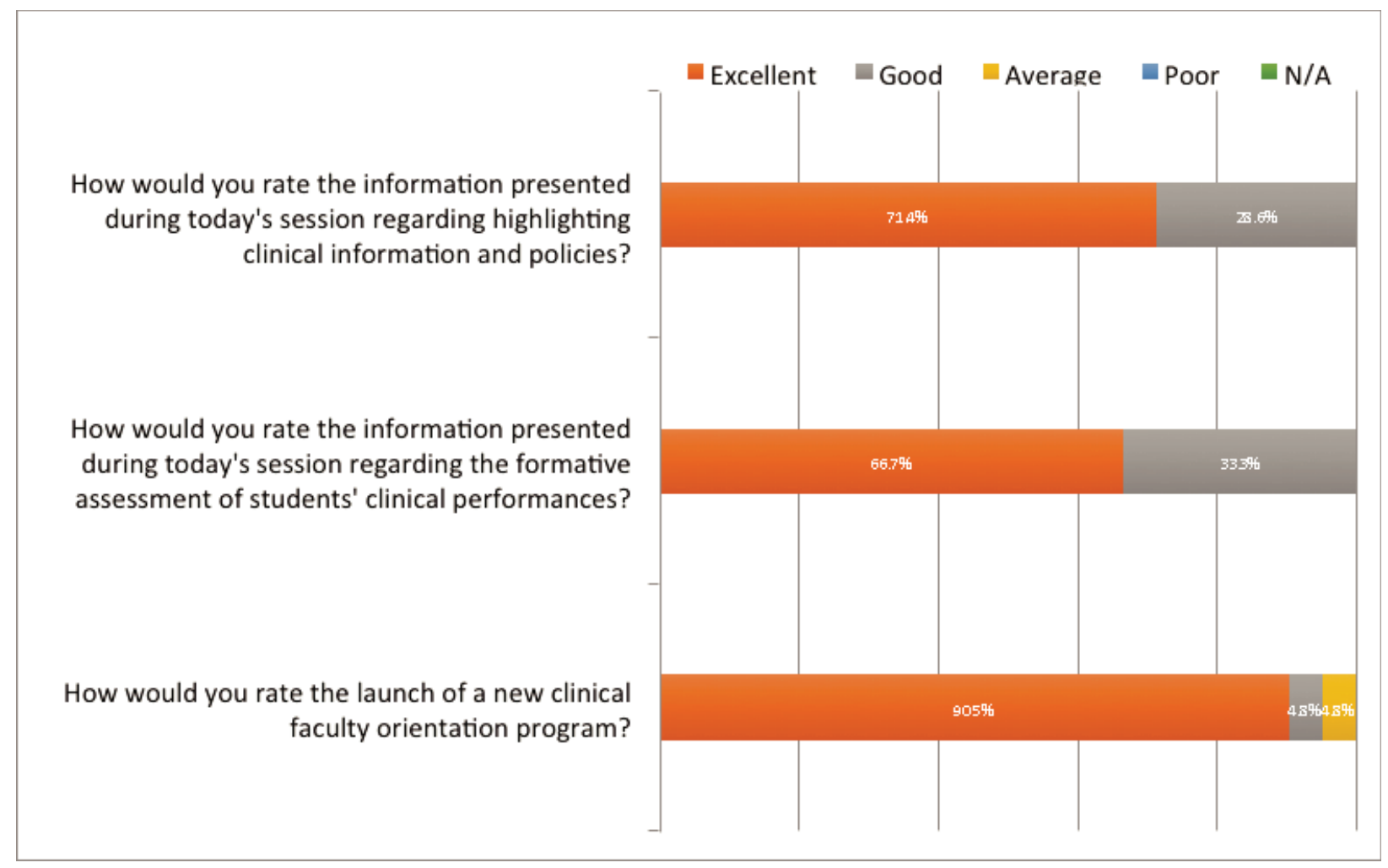

Figure 2. Post survey of part-time faculty members prior to introduction of New Clinical Faculty Training program $(\mathrm{N}=21)$ after receiving a brief description of the program

that lead to job resignation. ${ }^{9,13}$ In their study of the dental school work environment, Trotman et al. stated that "Clear expectations help to dispel anxiety associated with uncertainty over job performance" (p. 722). ${ }^{14}$ In a faculty survey conducted by Holyfield and Berry at Baylor College of Dentistry, 97\% of their respondents rated communication of job expectations as the most critical requirement for a new faculty orientation program, although their study focused on full-time faculty members. ${ }^{2}$ In our study, $66.7 \%$ of the part-time faculty members who did not experience the NCFT program rated as good or excellent the communication of their position expectations, while $23.8 \%$ rated it as average and $9.5 \%$ rated it as poor (SQ1). The NCFT committee wanted to improve communication with all new part-time faculty members as an important first step in increasing their job satisfaction and ultimately aiding in retaining qualified faculty. Though not a statistically significant difference $(p=0.109)$ for SQ1 on the comparison, the overall response from the intervention group regarding communication of position expectations increased, with $91.7 \%$ of the NCFT respondents giving an excellent or good rating.

Wilkerson and Irby noted that the goal of faculty development programs is to expedite effective teaching methods rather than allowing faculty members to grow via trial by error through personal experiences. ${ }^{6}$ At IUSD, information regarding clinical policies and procedures was available through various resources, but without an orientation program for new faculty members, they were left to acquire knowledge independently. The pre survey showed that $42.9 \%$ of the control group rated their training in clinical policies and procedures as excellent or good, with $19 \%$ rating it as poor and $4.8 \%$ rating it as not applicable suggesting they had received no training at all. Following the brief introduction to the NCFT program, the same cohort gave a $100 \%$ excellent or good rating regarding clinical information and policies provided in the program. This encouraging feedback supported the importance of this part of the 
Table 1. Pretest vs. posttest responses of part-time faculty members prior to introduction of New Clinical Faculty Training program $(\mathrm{N}=21)$ : knowledge of clinical policies

\begin{tabular}{|c|c|c|c|}
\hline Test Question & $\begin{array}{l}\text { Pretest } \\
\text { \% of Correct } \\
\text { Responses }\end{array}$ & $\begin{array}{c}\text { Posttest } \\
\text { \% of Correct } \\
\text { Responses }\end{array}$ & p-value \\
\hline $\begin{array}{l}\text { TQ1: A rubber dam is required for all direct restorations unless the student } \\
\text { determines it is not a possibility. }\end{array}$ & $52 \%$ & $95 \%$ & $0.003 *$ \\
\hline $\begin{array}{l}\text { TQ2: Routine periodontal procedures are to be initiated prior to any operative } \\
\text { or prosthodontic procedures unless approved by a faculty member. }\end{array}$ & $95 \%$ & $100 \%$ & 0.317 \\
\hline $\begin{array}{l}\text { TQ3: Stock trays may be used to take definitive impressions for any maxillary } \\
\text { or mandibular single crown preparation. }\end{array}$ & $62 \%$ & $76 \%$ & 0.083 \\
\hline $\begin{array}{l}\text { TQ4: Students may place resin core buildup material and take the definitive } \\
\text { impression within the same appointment, time permitting. }\end{array}$ & $76 \%$ & $100 \%$ & $0.025^{*}$ \\
\hline $\begin{array}{l}\text { TQ5: Definitive impressions making is not allowed (except under extraordinary } \\
\text { circumstances) after } 11: 15 \text { am or } 4: 15 \mathrm{pm} \text { to allow enough time for provisional }\end{array}$ & $90 \%$ & $100 \%$ & 0.157 \\
\hline
\end{tabular}
circumstances) after 11:15 am or 4:15 pm to allow enough time for provisional cementation, cleanup, and faculty approvals.

*Statistically significant difference

SQ1. How would you rate your experience when hired as an IUSD new faculty member regarding the communication of your position expectations?

SQ2. How would you rate your training as an IUSD new faculty member regarding general clinical information, policies and procedures?

SQ3. How would you rate your training as an IUSD new faculty member regarding assessing students' performances during clinical procedures?

SQ4. How would you rate your experience as an IUSD new faculty member regarding communication of credentialing requirements prior to your hiring start date?

SQ5. How would you rate your sense of appreciation from IUSD administration and faculty as a new faculty member?

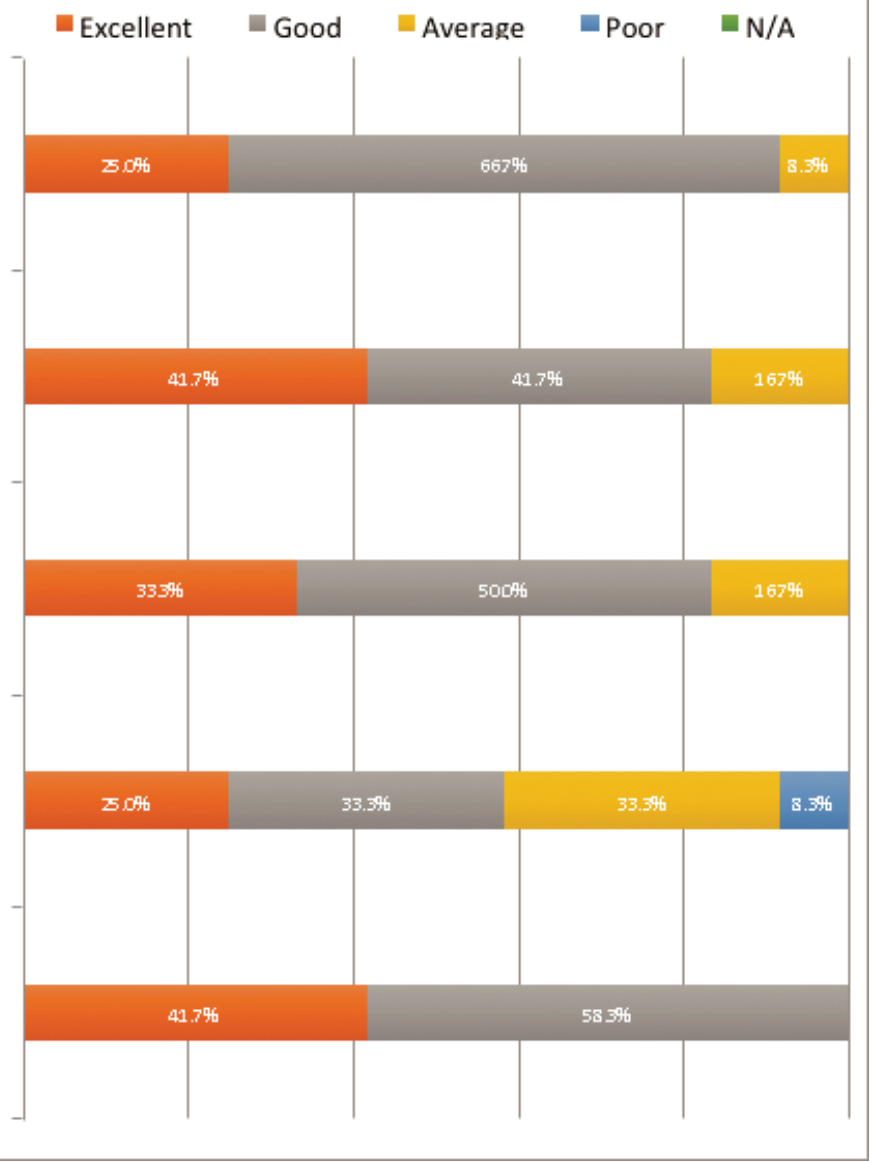

Figure 3. Follow-up survey of New Clinical Faculty Training program faculty members $(\mathrm{N}=12)$ : perceptions of program 
Table 2. Comparison of responses of part-time faculty members prior to introduction of New Clinical Faculty Training (NCFT) program $(n=21)$ and of faculty members who participated in the NCFT program $(n=12)$

\begin{tabular}{lc} 
Survey Question & p-value \\
\hline $\begin{array}{l}\text { SQ1: How would you rate your experience when hired as an IUSD new faculty member regarding the } \\
\text { Communication of your position expectations? }\end{array}$ & 0.109 \\
SQ2: How would you rate your training as an IUSD new faculty member regarding general clinical \\
information, policies, and procedures? \\
$\begin{array}{l}\text { SQ3: How would you rate your training as an IUSD new faculty member regarding assessing students' } \\
\text { performance during clinical procedures? }\end{array}$ & $0.005^{*}$ \\
$\begin{array}{l}\text { SQ4: How would you rate your experience as an IUSD new faculty member regarding communication of } \\
\text { Credentialing requirements prior to your hiring start date? }\end{array}$ & $0.008^{*}$ \\
$\begin{array}{l}\text { SQ5: How would you rate your sense of appreciation from IUSD administration and faculty as a new faculty } \\
\text { member? }\end{array}$ & 0.058 \\
*Statistically significant differences with better responses for the program group &
\end{tabular}

program. Comparison of the control group and NCFT intervention group results indicated a statistically significant difference $(p=0.005)$ for the question regarding training of clinical policies (SQ2), with better responses from the NCFT cohort. Among the NCFT participants, $83 \%$ rated this portion of the training as excellent or good, supporting the improvement in experiences for those who participated in the program.

To further support the inclusion of presenting important guidelines, teaching methods, and policies as part of the NCFT program, the control group's knowledge was assessed with a pretest and posttest. The findings from the pretest demonstrated that these faculty members were unfamiliar with some of the clinical policies and approved teaching methods. Following the NCFT presentation, they had a statistically significant increase on TQ1 $(p=0.003)$ and TQ4 ( $\mathrm{p}=0.025)$. The findings suggest that merely exposing the part-time faculty to the policies and accepted instructional methods helped increase their comprehension and awareness. Jacks et al. found that such programs may also help create a more calibrated faculty in dental hygiene. ${ }^{8}$

New faculty members should be calibrated regarding student evaluations to prevent frustration for students and faculty members alike as Garland and Newell found in dental hygiene education that variations in grading can adversely affect students' clinical performance and even affect patient care. ${ }^{7}$ In our pre survey, $38.1 \%$ of the control group rated their training in student assessment as excellent or good, but $14.3 \%$ reported no assessment training was provided; $100 \%$ of the same group gave an ex- cellent or good rating to the assessment training in the NCFT program after viewing the presentation. Similarly, $83.3 \%$ of the NCFT intervention group gave an excellent or good rating to their assessment training, suggesting it prepared them for clinical evaluation of students. On SQ3 (assessment training), the difference between the responses of the control group prior to learning about the program and the intervention group after having experienced the program was statistically significant $(\mathrm{p}=0.008)$. Calibration is a vital part of successful clinical assessment, and our findings suggest that strategies to address this issue should be included in new faculty development programs.

A study by Froeschle and Sinkford found that working relationships were the most commonly cited positive aspect of dental faculty members' work environment. ${ }^{15}$ As new faculty enter academia, the institution needs to be intentional in creating an atmosphere of appreciation, support, and collegiality. If this objective is not made a priority, it may lead to feelings of isolation or lack of mentorship for faculty, which was identified in a study by Rogér et al. as a negative aspect of dental academic careers. ${ }^{16}$ While, prior to introduction of the NCFT program, many of the IUSD part-time faculty members rated their sense of appreciation from the school's administration and faculty as average or above, $9.5 \%$ rated it as poor. To help prevent future faculty members from having a similar substandard experience, the committee has invested time and resources into helping new faculty members feel valued and part of the team with the overall mission of creating a positive work environ- 
ment. The results from the NCFT intervention group were favorable, with $100 \%$ rating their sense of appreciation as good to excellent.

Our results in this study suggest that the NCFT program is providing an enhanced new clinical faculty experience. Although the program has met some early successes, there are limitations that need to be addressed. The NCFT committee consisted of a small group of faculty and administrator volunteers to help implement the program, similar in design to the Baylor College of Dentistry orientation program. ${ }^{2}$ As IUSD continues to hire more part-time faculty members, the commitment necessary for the training program will likely become more time-consuming and cumbersome for those involved in the process. To address this problem, the committee should be expanded to include additional calibrated faculty volunteers who will embrace the mission of the NCFT program by welcoming new faculty members and providing them with guidance and mentorship.

The committee also recognizes a principal issue that must be addressed is the development of consistent follow-up sessions for the new faculty beyond the orientation process. Ongoing opportunities for meetings with the part-time faculty members can serve to emphasize important clinical concepts and policies, as well as provide opportunities for collaboration to reinforce positive working relationships. Additionally, these meetings should include calibration efforts to empower faculty members with the skills necessary to be successful teachers. Offering teaching sessions for new and seasoned faculty members is essential to keep them current in teaching methods in the dental school environment. ${ }^{14}$ Furthermore, for calibration training to be effective, it must be consistent and frequent, as was found in a study in dental hygiene education. ${ }^{7}$ In September 2016, a needs assessment survey was conducted to examine the state of part-time faculty needs at IUSD. The information gathered is being used in the development of customized part-time faculty programs, with the first iteration held in November 2016.

There were additional limitations with this study, primarily having to do with inconsistencies between the groups being compared. The control group consisted of only part-time faculty members, whereas the intervention group had both full-time and part-time faculty members, although the parttime members predominated. In addition, the control group members based their perceptions of the NCFT program on merely receiving a brief description, whereas the intervention group members based their responses on having experienced the entire program. While there is nevertheless some value in comparing the two group's results, as described above, the variation in experience makes their responses not directly comparable. Future research should apply more rigorous requirements on the study design to avoid these complications. Finally, since this study took place at one dental school and thus its findings may not be generalizable, further research should be undertaken with larger sample sizes and other dental institutions.

\section{Conclusion}

Based on the findings from this study, the hypothesis was supported that there was a need to improve our approach to training and communicating with new faculty members. As IUSD and other institutions continue to need to recruit and retain part-time clinical faculty members, the development of new faculty programs should be a priority and should be carefully adapted to the needs of each school's educators. Empowering part-time faculty members with the tools they need to be successful clinical teachers may lead to an increased sense of appreciation, create a more positive work environment, and ultimately, increase the number choosing to remain in academia. The preliminary outcomes of the NCFT program have been positive with a reported $93 \%$ retention rate of faculty participants since the program's launch in January 2014. The NCFT program also serves as the foundation for forthcoming part-time faculty development programs. Further research is planned to measure the effectiveness of providing part-time faculty members with customized development programs and their impact on transforming private practice dentists into dental educators.

\section{Acknowledgments}

The authors thank Dr. George Willis and Dr. David Brown for their support of IUSD's NCFT program.

\section{REFERENCES}

1. Wanchek T, Cook BJ, Slapar F, Valachovic RW. Dental schools vacant budgeted faculty positions, academic year 2014-15. J Dent Educ 2016;80(8):1012-22.

2. Holyfield LJ, Berry CW. Designing an orientation program for new faculty. J Dent Educ 2008;72(12):1531-43. 
3. Chapnick LA, Chapnick A. Clinical undergraduate teaching. J Endod 1999;25(10):686-8.

4. McAndrew M, Motwaly S, Kamens TE. Long-term follow-up of a dental faculty development program. J Dent Educ 2013;77(6):716-22.

5. Gadbury-Amyot CC, Smith DB, Overman PR, Bunce L. Faculty development at one midwestern dental school: a program evaluation. J Dent Educ 2015;79(10):1177-88.

6. Wilkerson L, Irby DM. Strategies for improving teaching practices: a comprehensive approach to faculty development. Acad Med 1998;73(4):387-96

7. Garland KV, Newell KJ. Dental hygiene faculty calibration in the evaluation of calculus detection. J Dent Educ 2009;73(3):383-9.

8. Jacks ME, Blue C, Murphy D. Short- and long-term effects of training on dental hygiene faculty members' capacity to write SOAP notes. J Dent Educ 2008;72(6):719-24.

9. Hessler K, Ritchie H. Recruitment and retention of novice faculty. J Nurs Educ 2006;45(5):150-4.
10. Bligh J. Faculty development. Med Educ 2005;39(2): 120-1.

11. Bland CJ, Seaquist E, Pacala JT, et al. One school's strategy to assess and improve the vitality of its faculty. Acad Med 2002;77(5):368-76.

12. Kirkup ML, Adams BN, Meadows ML, et al. Development and implementation of an electronic clinical formative assessment: dental faculty and student perspectives. J Dent Educ 2016;80(6):652-61.

13. Gormley DK. Factors affecting job satisfaction in nurse faculty: a meta-analysis. J Nurs Educ 2003;42(4):174-8.

14. Trotman CA, Haden NK, Hendricson W. Does the dental school work environment promote successful academic careers? J Dent Educ 2007;71(6):713-25.

15. Froeschle ML, Sinkford JC. Full-time dental faculty perceptions of satisfaction with the academic work environment. J Dent Educ 2009;73(10):1153-70.

16. Rogér JM, Wehmeyer MH, Milliner MS. Reflections on academic careers by current dental school faculty. J Dent Educ 2008;72(4):448-57. 